\title{
Patrick Vinton Kirch and Clive Ruggles, Heiau 'Āina Lani: The Hawaiian Temple System in Ancient Kahikinui and Kaupō, Maui
}

\author{
Honolulu: University of Hawaii Press, 2019. Hardback 384 pp. ISBN:
}

9780824878276. \$75.00.

\section{Martha H. Noyes}

Independent scholar

marthanoves@hawail.rr.com

This well-written book addresses archaeoastronomy of the Kahikinui and Kaupō regions of pre-contact Maui island. The two authors are highly respected, deeply experienced and widely published in their fields. Patrick Vinton Kirch, an archaeologist who was born and raised in Honolulu, received his PhD from Yale, and is a University of California Berkeley professor emeritus of archaeology as well as a current professor of anthropology at the University of Hawai'i, much of whose research and writings have centred on Polynesia. Clive Ruggles is a British archaeoastromer and a Leicester University professor emeritus, for whom Hawai'i has been of interest for several decades. I am familiar with works by both authors, I have met and conversed with both and have great respect for them.

In additon to presenting details of site archaeology in the Kahikinui and Kaupō regions of Maui, the authors seek to set out a case that astronomy was among the functions of Hawaiian heiau (temples), and using extensive data they argue for the presence of site orientations or alignments to astronomical objects or events. In addition, the authors state that the methods they used to suggest specific astronomical alignments or orientations will prove fruitful when applied to other sites in other regions.

The book, divided into two main parts, is meticulously researched, and findings are reported in great detail. Part I, which includes a wealth of black and white photographs and tables of data, analyses the various aspects of the heiau, with sections on their structure, types, chronology and function, as well as heiau viewsheds and orientations. Part II is a detailed catalogue of heiau sites in the areas under study.

Chapter 1 introduces the reader to the heiau and to the probability that they had some association with astronomy. It also describes the Kahikinui and Kaupo regions and overviews archaeological research conducted there, before addressing the authors' theoretical approach and their research methods. Chapter 2 discusses ethnohistory and 
archaeology of the study regions more specifically, and Chapter 3 describes the heiau in the region. Chapter 4 provides the authors' observations on heiau orientations, some general information on stars and the Sun in observational astronomy, viewsheds from heiau sites in the study areas - including notable topographic features that may have had celestial significance - and presents the authors' determinations that some stars and constellations were of significance, notably the Pleiades, Sirius, Aldebaran, the Hyades, the Belt of Orion and Pollux, and also some Sun events, such as the June solstice sunrise. Chapter 5 summarises the previous chapters and concludes that detailed data-driven studies such as that of the authors' "three-stage" approach - systematic analysis followed by contextualised interpretation, together with impartial presentation of the basic archaeoastronomical "facts" (p. 138) will result in fruitful understanding of the relationship between Polynesians and the sky.

The catalogue in Part II is presented in three chapters, the first two addressing in turn the Auwahi to Alena and Kipapa to Manawainui areas of Kahikinui, and the third the Kaupō moku. These three chapters - which together make up almost 200 pages - describe each heiau in terms of location and topographic setting, architecture, excavation, dating and chronology, archaeological context, viewshed, and orientation or lack of orientation to astronomical bodies, followed by any additional remarks.

I have a deep appreciation both for the detailed data and for the number of years over which that data was gathered. Not all of the data over all of the years of study, particulary the early years of Patrick Kirch's archaeological work before he became involved in archaeoastronomy, was gathered primarily for the study of the Kahikinui and Kaupō regions' possible astronomical associations, but this book has nevertheless gained considerably from that earlier research. I should say here that I have been researching astronomy associated with Kūkaniloko, a site in central O'ahu, for 12 years (and ongoing, see for example Noyes 2018). The site is admittedly very different from those the authors researched - Kükaniloko is the acknowledged piko (navel, centre) of the island of O'ahu, known as Kāne temple, and was known to have equinoctial associations with a mountain in the east (Puu Kaaumakua) and a mountain in the west (Mauna Kaala), over which the equinox Sun rose and set respectively. Also, I am not an archaeologist; I am a cultural astronomer.

In 1992 there was an exchange of essays between the anthropology professor Keith Kintigh and the pioneering archaeoastronomer Anthony Aveni. The essays were published in Archaeoastronomy and Ethnoastronomy News, with Kintigh's piece in the September equinox issue and Aveni's response in the December Solstice issue.

Kintigh's concern was that archaeoastronomers went looking for astronomical alignments without any regard for the cultural meaning(s) of those alignments. Archaeoastronomers, he opined, were alignment hunting, a kind of "butterfly collecting", looking for astronomical specimens that were interesting but not addressing cultural significance (Kintigh 1992). He said that "the observation of an alignment, however ingenious, is in and of itself not interesting". He went on to say that it was important to provide "rigorous and testable arguments linking archaeoastronomical observations with serious anthropological questions" (Kintigh 1992). 
Aveni replied that archaeoastronomy had progressed and was progressing and becoming more interdisciplinary. He admitted, however, that Kintigh's criticisms of archaeoastronomy had some truth. He said that archaeoastronomers "will need to escalate their work to address culturally substantive questions" (Aveni 1992). He added that "this is hard work, and moreover, it requires a change of intellectual life style that many professionals may not be willing to make." This exchange of essays has been seminal for archaeoastronomy, and of course for cultural astronomy. It calls for greater incorporation of the cultural characteristics and functions of celestial objects and events, and that means an emphasis on ethnoastronomy equal to that of orientations and alignments. However, that emphasis is missing in the book, except in the case of the Pleiades and, to a lesser extent, Sirius.

Most stars have more than one Hawaiian name, although the authors tend to rely on only one (Makalii) for the Pleiades and three for Sirius: Aa, Hokukelewaa, and Loaa ke kane. Loaa ke kane is incorrect, and its inclusion is my fault. The phrase, which I've included in published works, is, as was recently pointed out to me by Kalei Nuuhiwa, a fluent Hawaiian speaking scholar, from a passage in the Kumulipo creation chant and refers to Sirius as the husband, the kane, of another star. For other stars for which they report alignments - Pollux, Aldebaran, the Belt of Orion, Spica, Cassiopeia, Altair and the Hyades - they offer only one name for each although all of them have more than one Hawaiian name. The Hawaiian names of stars have meanings and most, if not all, of those meanings are relevant to understanding the star's cultural use and importance.

Alignments to the Pleiades are the most frequent of the alignments the authors found. The Pleiades are typically thought to reference the annual Makahiki season, which they do, but this is not all that the Pleiades signify. For all regions in the Hawaiian islands, including those regions that did not celebrate Makahiki, the Pleiades are more general season markers, delineating the change from Kau Wela (summer) to Hooilo (winter) and back from Hooilo to Kau Wela. The authors also note that the rises of the Pleiades occur at or very close to the rise location of the June solstice Sun, an event that is unrelated to Makahiki. The June solstice "season" is the period of the year during which the deceased are able to return to visit the living, thus a time of consequence and importance, especicially in Kāne religious tradition (Noyes 2018, 206).

The authors also point out alignments to the rise of Pollux, the Hyades and Aldebaran, but do not offer any cultural significance for these alignments. Why did pre-contact Hawaiians want to know about the rise of these stars? I can suggest one reason from my work at Kūkaniloko - the evening rise of Pollux, Aldebaran and the Hyades (of which Aldebaran is a member star) indicate solar nadirs, when the Sun is $90^{\circ}$ below the horizon and thus cannot be observed. The evening rise of Pollux indicates the January solar nadir, and the evening rise of Aldebaran and the Hyades indicate the November solar nadir.

The cultural meanings, uses, characteristics and functions of pre-contact Hawaiian cultural astronomy are complex and interwoven. I point that out not to make less of the reviewed book, but to suggest that detailed archaeological excavation is not necessarily crucial to archaeoastronomy. Quantifiable data alone cannot offer understanding of these, or of the interrelationships among stars and between stars and the Sun. To compre- 
hend the cutural significance of astronomical objects and events requires research into and knowledge of their cultural implications. While hard data may suggest such further research, it does not sufficiently provide the cultural expressions and consequences of Hawaiian astronomy.

The authors' certainty that detailed archaeological data is crucial for identifying possible astronomical orientations and alignments seems to devalue ethnoastronomical research. Such research certainly has quantifiable elements, but also necessarily includes non-quantifiable elements. These latter include star names, as indicated above, but also genealogies, cosmogonies, chants, mo'olelo (stories, histories, legends, myths) and both localised and non-localised and place names associated with an archaeological site.

While I offer my criticisms as caveats about the limits of hard data in understanding Hawai'i's pre-contact astronomical knowledge, I admire this well-written book and the authors' outstandingly detailed research. The book is a valuable resource both as an instructive text on archaeoastronomical research and as a compendium of sites in the Kahikinui and Kaupō regions of Maui. It will be an excellent text for undergraduate and graduate students, a useful reference for scholars and, despite the use of technical archaeological and astronomical terms, an enlightening work for the layperson.

\section{References}

Aveni, A., 1992. “Nobody Asked, But I Couldn't Resist: A Response to Keith Kintigh on Archaeoastronomy and Archaeology". Archaeoastronomy and Ethnoastronomy News 6 (December solstice).

Kintigh, K., 1992. "I Wasn't Going to Say Anything, But Since You Asked: Archaeoastronomy and Archaeology". Archaeoastronomy and Ethnoastronomy News 5 (September equinox 1992).

Noyes, M., 2018. "Solar Nadirs in Pre-Contact Hawaiian Cultural Astronomy". Journal of Skyscape Archaeology 4 (2): 201-228. https://doi.org/10.1558/jsa.34369 